\title{
A Educação Ambiental como instrumento para a adoção da Gestão Ambiental: o perfil de pequenas empresas do setor comercial de Aracaju
}

O presente estudo procura verificar se o nível da educação ambiental dos gestores de organizações localizadas no centro comercial da cidade de Aracaju (SE), selecionadas para este, tem haver com a adoção de práticas sustentáveis no cotidiano destas pequenas empresas. O foco direcionou-se para as empresas de tal porte, pois, é notória sua importância para a economia local principalmente no que se refere à empregabilidade. Trata-se de um estudo de natureza mista, onde foi aplicado um questionário e entrevista aberta com os gerentes das organizações. Por fim, após análise dos dados coletados, evidenciou-se que o nível de educação ambiental (EA) dos envolvidos é baixo e que as práticas ambientais adotadas também não são bem fundamentadas, assim como pouco eficazes. Desta feita, podemos associar que uma EA é de fundamental importância para um gestor incentivador de atos ambientalmente corretos.

Palavras-chave: Educação Ambiental; Gestão Ambiental; Pequenas Empresas.

\section{Environmental Education as an instrument for the adoption of Environmental Management: the profile of small companies in the commercial sector of Aracaju}

\begin{abstract}
This study aimed to verify that the level of environmental education of managers of organizations located in the commercial center of the city of Aracaju (SE), selected for this has to do with the adoption of sustainable practices in the daily life of these small businesses. The focus directed to the size of such companies as striking is its importance to the local economy especially with regard to employability. It is a study of a mixed nature, where it was applied a questionnaire and open interviews with managers of organizations. Finally, after analyzing the collected data, it became clear that the level of environmental education (EE) of those involved is low and that environmental practices are also not well-founded, as well as ineffective. This time, we may associate that an EA is of fundamental importance to a supportive manager environmentally friendly actions.
\end{abstract}

Keywords: Environmental Education; Environmental management; Small Business.

Topic: Sistemas de Gestão Ambiental

Reviewed anonymously in the process of blind peer.
Received: 05/01/2016

Approved: 10/04/2016
Luis Claudio dos santos Bastos Júnior Universidade Federal de Sergipe, Brasil http://lattes.cnpq.br/9426245633389734 lbastosjr@gmail.com

Roseli Pereira Nunes

Universidade Federal de Sergipe, Brasil http://lattes.cnpq.br/0381794776219071 roseli.aju@gmail.com

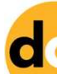

DOI: $10.6008 / S P C 2179-6858.2016 .002 .0016$
Referencing this:

BASTOS JÚNIOR, L. C. S.; NUNES, R. P.. A Educação Ambiental como instrumento para a adoção da Gestão Ambiental: o perfil de pequenas empresas do setor comercial de Aracaju. Revista Ibero-Americana de Ciências Ambientais, v.7, n.2, p.197-207, 2016. DOI: http://doi.org/10.6008/SPC2179-6858.2016.002.0016 


\section{INTRODUÇÃO}

A sociedade vem buscando a cada dia um melhor entendimento acerca das questões ambientais. Neste sentido, muitos debates surgem a fim de buscar evidenciar a responsabilidade de todos os atores envolvidos com o meio ambiente, e é neste contexto que Mendonça (2004) aponta que a compreensão da temática meio ambiente tem variado bastante no último século, a partir das duas últimas décadas a conotação naturalista foi ampliada de maneira que deixou de se referir somente aos componentes físiconaturais, passando a envolver também aspectos sociais.

Diante desta realidade, Tauk (2003) enfatiza o fato de o impacto ambiental ser referente exclusivamente a ação do ser humano no meio natural o que, nos últimos anos, tem refletido em uma postura mais crítica da sociedade frente aos chamados 'degradadores da natureza', o que, implicitamente, já direciona à concepção de mudanças nas práticas que visam o progresso e as questões econômicas.

Nesse sentindo a educação ambiental surge como uma forma de despertar nas pessoas novas reflexões acerca da importância em contribuir com um ambiente mais saudável, equilibrado e sustentável para todos, pois, tal ferramenta é hábil em possibilitar a transformação de atitudes. Logo, quanto mais cedo o indivíduo tiver contato com as assertivas ambientais, mas fácil de ser evidenciar um adulto consciente de seu papel na sociedade nos mais diversos contextos.

Com relação à postura das organizações, Barbieri et al. (2010) relatam que a aderência delas às questões ambientais e ao desenvolvimento sustentável iniciou primeiramente de fora para dentro, contrariamente ao verificado no movimento pela qualidade, que sofreu uma grande expansão principalmente a partir dos anos 80 . Esta adesão é uma reposta aos anseios das inúmeras instituições e da sociedade civil organizada, que culpa as empresas pelo processo de aviltamento social e ambiental que permeia o planeta.

Apesar disto, assim como a gestão ambiental, que já é uma realidade em muitas empresas, a adoção de práticas socialmente aceitas também já não tem sido vista como uma obrigação, pois, de acordo com Barbieri et al. (2010), só recentemente a adesão das empresas passou a ser induzida por fatores de natureza empresarial ou, dito de outra forma, fazer parte desse movimento passou a ser um fator de competitividade.

Desta feita, as empresas buscam cumprir todas as exigências dos órgãos fiscalizadores no intuito de associar sua marcar à recente ideologia da gestão verde. “As organizações que através de sistemas de gestão ambiental eficientes, obtêm resultados significativos, alcançam seus reconhecimentos através de certificações de qualidade ambientais" (BENEDITO et al., citato por BA, 2003), pois com esta ação, a organização tem o reconhecimento da sociedade e dos órgãos públicos, aumentando sua credibilidade.

Diante do exposto, surge o interesse de realizar essa pesquisa, que teve como objetivo analisar o nível de conhecimento dos gestores das organizações pesquisadas no que se refere à educação ambiental e verificar se tal aspecto é responsável por uma adoção de práticas sustentáveis nas empresas. O trabalho é composto por cinco seções. A que segue a esta introdução é a revisão teórica que aborda o conteúdo 
pertinente ao estudo. A seção seguinte descreve a metodologia que norteou a pesquisa. Logo após, a análise dos resultados e as conclusões.

\section{REVISÃO TEÓRICA}

\section{Educação Ambiental}

As sociedades modernas vivenciam o aumento das populações e/ou do consumo de alimentos e objetos pessoais, que muitas vezes incrementaram também os problemas ambientais. Diante de tal realidade, os poderes públicos buscam promover políticas públicas em prol de um meio ambiente de qualidade para a população. Mas isso não é um papel apenas do poder público, e sim da sociedade, das organizações e das empresas.

Para despertar a preocupação em praticar a responsabilidade ambiental, destaca-se a necessidade da realização de um trabalho de sensibilização com a sociedade mediante a educação ambiental, considerada como tarefa essencial para a vida humana, que costuma ser praticada nas escolas, mas que também pode e deve acontecer em diferentes ambientes não-escolares como hospitais, organizações não governamentais, empresas, dentre outros.

Reigota (2009) em seu livro 'O que é Educação Ambiental', caracteriza esta como uma educação política, visto que a mesma está comprometida com a ampliação da cidadania, da liberdade, da autonomia e da intervenção direta dos cidadãos em prol de soluções e alternativas que permitam a convivência equilibrada e voltada para o bem comum.

Para Ranauro (2003) a reflexão da prática de educação ambiental pode ser entendida como uma análise da ética nas práticas educativas mediante o respeito existente na relação entre os saberes dos educadores com os saberes dos educandos. Neste contexto, faz-se necessário refletir acerca da relação "simbólica" existente entre a educação ambiental e os saberes locais das comunidades e/ou grupos alvos de programas/projetos. Esta relação de troca de saberes enriquece toda a prática, fazendo com que os envolvidos se sintam capazes de participar de forma ativa das ações em prol da mitigação dos problemas ambientais.

Corroborando com o supracitado autor, Goodfellow (2000) acrescenta que nos últimos anos a sociedade tem exigido que todos nós os tornemos mais conscientes de nossa responsabilidade em relação aos recursos naturais da Terra, a fim de assegurar que estes recursos estejam disponíveis para futuras gerações. Assim, o autor destaca que "grande parte desta responsabilidade recaiu sobre as empresas, pois, suas ações tendem a causar grandes impactos nos contextos ambientais sejam eles naturais ou não" (GOODFELLOW, 2000).

Nesta perspectiva, Pedrini (2008) destaca a relevância de práticas da educação ambiental no ambiente empresarial, pois, "a maioria das empresas atenta-se aos lucros e acaba esquecendo-se das responsabilidades socioambientais perante a sociedade, além de danos irreversíveis ao mundo". 
Segundo o citado autor, é comum observar que a educação ambiental na empresa é uma prática desconhecida pela maioria das organizações, pois tal preocupação ainda é um fato novo no âmbito empresarial. No entanto, apesar da educação ambiental ainda não ser uma prática ativa nas empresas, esta vem sendo apontada como fator que aumenta a credibilidade da organização em relação à sociedade. Para tanto, é imprescindível a intervenção de especialistas na área ambiental a fim de promover o processo de formação dos funcionários. Neste sentido, Alfenas (2004) afirma que:

Não é nenhuma novidade o fato de que a qualidade dentro de uma organização está intimamente ligada a aspectos culturais. A forma com que cada funcionário vê a implantação de um programa de qualidade ambiental é determinada pelo conjunto de experiências e vivências pessoais que foram sendo acumuladas ao longo de sua vida. Diante desta realidade é que os programas de qualidade devem ser adaptados de acordo com o porte da empresa, do empreendimento e a cultura local para que possam alcançar êxito.

A literatura pertinente a esta temática tem mostrado que motivar e capacitar as pessoas para a prática de ações referentes à educação ambiental tem se revelado uma importante ferramenta da gestão ambiental, permitindo que as pessoas conheçam, compreendam e participem das atividades propostas, assumindo postura proativa em relação a tal problemática.

A pesquisa de campo realizada neste trabalho demonstra que nada adianta inserir nas empresas termos e nomenclaturas referentes às questões ambientais e/ou cobrar dos funcionários ações de educação ambiental, sem que eles saibam do que se trata. Para tanto, os colaboradores só saberão a importância de cumprirem com as atividades de gestão ambiental se for explicado a eles a relevância das práticas. Ou seja, para que as empresas consigam tal compromisso de todos com a gestão ambiental, é necessário que ela forneça, além de recursos e equipamentos de controle ambiental, conhecimentos básicos sobre meio ambiente e gestão ambiental, bem como o auxílio na identificação e controle das principais causas de impactos ambientais da sua atividade.

\section{Gestão Ambiental}

Nota-se nos dias hodiernos uma comunidade cada vez mais consciente de seu papel ambiental, esta evolução do pensamento surge após debates e maior acesso às informações referentes à temática. Nesta perspectiva, surge um consumidor também mais exigente que busca empresas que adotem uma postura mais responsável para com as questões ambientais. Calixto (2006) coloca que a sociedade tem cobrado maior atitude das empresas acerca das questões ambientais, principalmente as mais poluidoras. Com isso, as organizações que adotem uma 'Gestão Ambiental' como valor norteador de suas ações, saem como diferencial de mercado. Corroborando com esta ideia, Campos et al. (2006) afirmam que há um crescimento na importância da responsabilidade ambiental no modo de gerir as organizações.

Pozo et al. (2007) acrescentam que adoção da 'Gestão Ambiental' por parte das organizações é uma resposta ao novo perfil do cliente verde e ecologicamente interessado nas temáticas ambientais, assim, a procura constante por minimizar as ações degradantes tornou-se uma estratégia de fundamental importância para as empresas se manterem competitivas no mercado com tanta concorrência (BENEDITO et al., 2011). 
O termo gestão ambiental é entendido como "o conjunto das diretrizes e atividades administrativas e operacionais realizadas com o objetivo de obter efeitos positivos sobre o meio ambiente" (MARTINS et al., 2011). De acordo com Steffen et al. (2012) uma das formas da organização seguir um comportamento ético ambiental é implementar a Gestão Ambiental. Neste sentido Campos et al. (2006) colocam que este sistema de gestão tem como propósito promover nas organizações formas de prevenir a poluição, melhorar os aspectos ambientais e atender aos requisitos legais. $O$ sistema de gestão ambiental é uma ferramenta valiosa para os gestores reduzirem os impactos que suas organizações geram ao meio ambiente, e dessa maneira aumentar a receita e criar novas oportunidades de negócios.

Para a implantação de um Sistema de Gestão Ambiental (SGA) dentro de uma organização, faz-se necessário o comprimento de 17 requisitos básicos que devem ser inseridos de forma a gerar uma melhora continua na relação estabelecida entre a produção e a responsabilidade socioambiental, uma vez que os investidores procuram por empresas socialmente responsáveis para aplicação de seus recursos. Acredita-se que as empresas com estas características e perfil estejam melhor preparadas para lidar com os riscos econômicos, sociais e ambientais (SILVA et al., 2010).

Desta feita, há a necessidade de qualificar, mediante a concessão de certificados, as organizações que tem a 'Gestão Ambiental' inserida no seu cotidiano. Os selos ambientais fazem parte das metas das organizações, pois o Instituto Ethos (2009) evidencia o crescimento no número de certificações adquiridos por organizações brasileiras como as normas ISO, porém, o aparecimento de novos certificados associado à responsabilidade social como as normas SA800 (relação de trabalho) e a AA100 (referente ao diálogo com partes interessadas), é um desafio para empresas aumentar seus desempenhos.

Os 'empreendedores sustentáveis' já idealizam e planejam seus negócios apoiados nas práticas de 'Gestão Ambiental' e se utilizam desta ferramenta como estratégia de marketing para atrair, cativar e fidelizar seus clientes. Apesar dos avanços pontuados, Galvão et al. (2009) destacam que o estabelecimento de uma gestão ambiental nas empresas é um processo lento que requer certa tolerância dos investidores e interessados, pois no Brasil, assim como nas economias subdesenvolvidas, a responsabilidade ambiental demorou a ter lugar de destaque para os gestores.

Neste sentido, ainda se evidenciam muitas empresas que não entendem à 'Gestão Ambiental' como um ganho, principalmente no que se refere a redução de custos e marketing. Essa realidade é mais forte nos empreendimentos de pequeno e meio porte, no quais os gestores geralmente não possuem uma formação ambiental mais enraizada, logo, a falta de práticas de 'Gestão ambiental' nos pequenos negócios pode ser associada a uma educação ambiental insuficiente por parte dos idealizadores e gestores da organização.

\section{Pequenas Empresas e a Gestão Ambiental}

Oliveira (2006) afirma que no período de 5 anos no Brasil, correspondendo ao intervalo entre 1995 e 2000, a cada 100 novos empregos gerados, apenas 4 estavam nas media e grandes empresas, sendo que 0 restante se encontra nas micro e pequenas. Estes números poderiam ser maiores se levassem em consideração os empregos informais. Assim, as pequenas empresas que atuam no setor comercial das 
cidades são as que vêm tendo maior expansão, e isto se deve à maior viabilidade do estabelecimento em função dos menores investimentos e qualificação dos profissionais envolvidos. Estes pequenos negócios atendem geralmente as necessidades básicas dos consumidos e estão melhor distribuídos dentro do território nacional.

Nas pequenas empresas, pelo fato de seus gestores e pensadores ficarem mais próximos dos clientes, têm-se a possiblidade de entender melhor a demanda dos consumidores ambientalmente conscientes e assim tornar seu negócio um diferencial de mercado, pois, o "meio empresarial, parte integrante e ativa dentro dessa realidade, busca formas de melhorar seu relacionamento com o meio ambiente e a sociedade" (BORGES et al., 2012). Com tudo, essa percepção parte primeiramente de um aprofundamento nas questões ambientais quem podem ser adquiridas através de uma melhor compreensão acerca dos ensinamentos da educação ambiental.

O SEBRAE (2012) realizou 3.912 entrevistas com empresários de micros e pequenas empresas em todo país a fim de verificar o conhecimento dos mesmos sobre as temáticas ambientais. Foi constatado que $65 \%$ têm um conhecimento médio e $2 \%$ disse não conhecer as temáticas abordadas. Ainda de acordo com a mesma pesquisa, entre os entrevistados consultados, grande parte pratica ações sustentáveis como: coleta seletiva lixo (70,2\%); contenção do consumo de papel (72,4\%); contenção do consumo de água (80,6\%); contenção de consumo de energia $(81,7 \%)$. Desta feita, nota-se na pesquisa a falta de um conhecimento mais aprofundando acerca das temáticas ambientais, pois apenas são pontuadas as práticas de ações de curto prazo, direcionadas para a redução de custos.

\section{METODOLOGIA}

O presente trabalho tem como premissa verificar o nível de conhecimento acerca da educação ambiental de 40 gestores de pequenas empresas localizadas no centro comercial de Aracaju (SE), e identificar se tal fato tem relação com a adoção ou não de práticas de gestão ambiental na organização.

Trata-se de uma pesquisa de natureza mista (quantitativa e qualitativa). A parte quantitativa tem como papel traduzir em números as opiniões e as informações obtidas mediante os instrumentos de coleta de dados, e no que se refere ao aspecto qualitativo, analisar a relação dinâmica verificada entre o mudo real e o sujeito (MORESI, 2003). Para tanto, foram utilizados procedimentos técnicos para coletas de dados, além de pesquisa bibliográfica e levantamento referencial.

O caráter qualitativo refere-se a uma análise que depende de alguns fatores como [...] natureza dos dados coletados, a extensão da amostra, os instrumentos de pesquisa e os pressupostos teóricos (GIL, 2002), neste sentido, pode-se conceituar este processo como uma sequência de atividades que inclui reduzir, caracterizar e interpretar mediante a exposição escrita.

O método quantitativo foi utilizado para a compreensão dos dados obtidos na pesquisa de campo através da análise estatística, representados através de gráficos analíticos que conforme Marconi et al. (2003) têm como objetivo, além de fornecer informações acerca do objetivo estudado, possibilitar ao pesquisador 
obter dados para posterior interpretação. O "papel do método estatístico é, antes de tudo, fornece uma descrição quantitativa da sociedade" (MARCONI et al., 2008).

Concretamente, a pesquisa preocupou-se em analisar os valores numéricos e a respostas levantadas a partir das entrevistas abertas e dos questionários fechados aplicados aos gestores, interpretando-os de maneira que se estabeleça uma correlação entre a realidade e o referencial teórico, e para isso, o "pesquisador deverá estar habilitado a proceder à vinculação entre os resultados obtidos empiricamente e as teorias que possibilitam a generalização dos resultados obtidos" (GIL, 2002). O estudo também pode ser classificado como descritivo, pois, evidenciam-se enfoques metodológicos que procuram determinar opiniões ou projeções futuras nas respostas obtidas dos gerentes das pequenas empresas.

Segundo Gil (1987), este tipo de pesquisa tem por objetivo básico descrever as características de determinada população ou fenômeno, e estabelecer possíveis relações entre variáveis através do levantamento de opiniões, atitudes, crenças e percepções de uma população sobre determinada situação. Neste aspecto, outro sentido atribuído a este trabalho é ser exploratório, isto é, foi realizado em uma área de pouco conhecimento acumulado e sistematizado que, de acordo com Gil (2002), pesquisas exploratórias têm com "objetivo principal o aprimoramento de ideias ou a descoberta de intuições".

Para a escolha das pequenas empresas do setor de comercio objetos deste estudo foram selecionadas atendendo algumas especificidades dentro do grupo ao qual pertencem como: Empresas de pequeno porte segundo a classificação do SEBRAE; Empresas dentro do setor do comercio; Acessibilidade e serem de Aracaju (SE). A pesquisa adotou o critério do Serviço Brasileiro de Apoio a Micro e Pequenas Empresas (SEBRAE) que para setor de comercio, que considera como sendo pequenas empresas aquelas que possuem de 10 a 49 empregados (SEBRAE, 2010).

\section{RESULTADOS}

\section{Características dos Entrevistados}

Os 40 gerentes participantes da pesquisa responderam a seis (6) perguntas que objetivavam a identificação das características pessoais, sendo o intuito desta seção do questionário o levantamento do perfil dos entrevistados e a análise das similitudes com outras características apontadas em respostas posteriores (Tabela 01).

Tabela 01: Características dos Entrevistados.

\begin{tabular}{|l|l|l|}
\hline \multirow{2}{*}{ Sexo } & Masculino & Feminino \\
\cline { 2 - 3 } & 28 & 12 \\
\hline \multirow{2}{*}{ Idade } & De $\mathbf{2 0}$ a $\mathbf{3 0}$ anos & Acima de $\mathbf{3 0}$ anos \\
\cline { 2 - 3 } & 9 & 31 \\
\hline \multirow{2}{*}{ Formação } & Ensino médio completo & Ensino superior \\
\cline { 2 - 3 } & 38 & 2 \\
\hline \multirow{2}{*}{ Tempo de Organização } & De $\mathbf{5}$ a $\mathbf{1 0}$ anos & Acima de $\mathbf{1 0}$ anos \\
\cline { 2 - 3 } & 10 & 30 \\
\hline \multirow{2}{*}{ Como começou na organização } & Funcionário & Gerente \\
\cline { 2 - 3 } & 40 & 0 \\
\hline \multirow{2}{*}{ Parentesco com o Proprietário } & Sim & Não \\
\cline { 2 - 3 } & 5 & 35 \\
\hline
\end{tabular}


Observa-se na Tabela 01 que 70\% dos entrevistados são do sexo masculino e 95\% possuem apenas o ensino médio completo. Ambos os fatos são considerados comuns aos pequenos negócios do setor comercial, onde é notório o predomínio de homens nos cargos de gerencia e, de igual maneira, observa-se como corriqueiro o fato de a maioria destes não possuir ensino superior. Ainda de acordo com os dados acima, verifica-se que $100 \%$ dos gerentes começaram como funcionários, isso demostra que o cargo de gerente nessas empresas é ocupado por antigos funcionários.

\section{Educação Ambiental}

Essa etapa do questionário buscou identificar nas repostas e nas falas dos entrevistados o nível de entendimento deles acerca da educação ambiental, mediante a realização de 6 perguntas de amplitude geral e abertas, a citar: $\mathrm{O}$ que você entende por natureza? Para você o que é meio ambiente? Qual a relação do homem com o entorno? Conceitue Educação Ambiental? A quem cabe a execução de ações e práticas de educação ambiental? Qual o papel dos gestores, dos educadores e dos sujeitos diante das problemáticas ambientais?

Mediante estes questionamentos, foi possível identificar o pouco conhecimento dos participantes sobre as questões ambientais com ênfase no fato de $80 \%$ deles (32) apresentarem conceitos de meio ambiente estritamente relacionado unicamente à natureza - fauna e flora - excluindo o homem deste contexto e, assim, desconsiderando a relação de troca constante existente entre os seres humanos e a natureza biofísica. Assim, natureza, meio ambiente e homem/entorno foram compreendidas pela maioria deles como coisas distintas que não interagem e interferem direta e ativamente nas ações cotidianas nos mais diferentes contextos socioeconômicos.

Quando questionados de forma direta acerca do conceito de educação ambiental, prevaleceu à concepção de prática educacional direcionada para as crianças a ser desenvolvida no ambiente escolar. Apenas 15 dos 40 entrevistados sinalizaram nas respostas a relevância da educação ambiental em diferentes contextos como o familiar e o profissional, dando ênfase às ações de respeito e solidariedade ao próximo, e redução de desperdícios com materiais de uso pessoal e coletivo.

Diante do conhecimento restrito demonstrado pela maioria dos entrevistados nas respostas sobre natureza, meio ambiente e educação ambiental, $80 \%$ atribuiu aos professores e aos gestores públicos a função de executar práticas e ações acerca das problemáticas ambientais.

\section{Gestão Ambiental}

No último bloco de perguntas do questionário, buscou-se levantar quais as práticas sustentáveis são adotadas pelas organizações participantes da pesquisa, foram feitas as seguintes perguntas: Quais as práticas sustentáveis adotadas? Qual o entendimento sobre gestão ambiental? Você conhece alguma norma ou lei ambiental? Você conhece alguma certificação ambiental? Você acredita que a adoção de uma gestão ambiental pode atrair mais clientes? A empresa se preocupa em um ambiente saudável para os funcionários? 
De acordo com os dados do Gráfico 01, podemos notar que os costumes adotados pelos gestores no cotidiano administrativo das organizações estão relacionados com a diminuição das despesas fixas. Assim, a noção de sustentabilidade estaria diretamente relacionada à economia em termos financeiros de curto prazo, ficando evidente na entrevista que nenhuma organização adota um planejamento voltado para a gestão ambiental.

Conforme dados apresentados pelo SEBRAE (2012), trata-se de uma característica comum das pequenas empresas, uma vez que estas organizações tendem a atuar com margens de lucros menores e, em função disto, buscam em suas rotinas ações em prol de economias evitando desperdícios. Ainda neste sentido, pode-se destacar que as principais práticas verificadas nas empresas participantes (Gráfico 01).

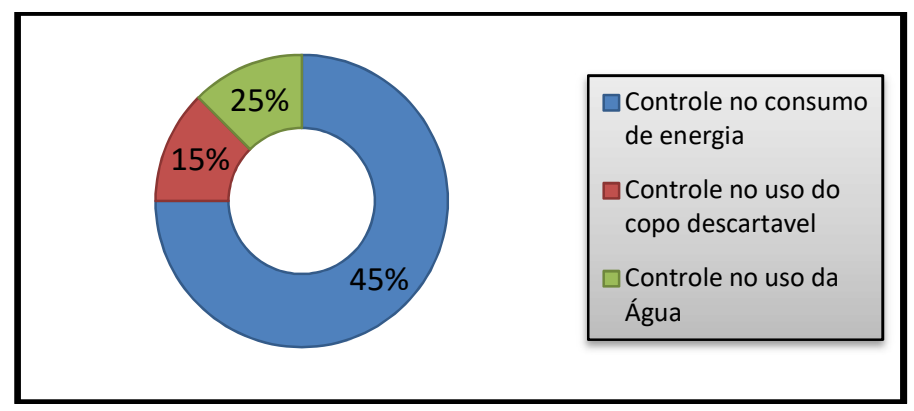

Gráfico 01: Práticas sustentáveis adotadas.

As perguntas referentes a um entendimento sobre a gestão, normas, leis e certificação ambiental, tiveram uma negativa por todos os entrevistados, pois mesmo os gerentes com nível superior demostraram um baixo conhecimento acerca da questão. Neste sentido, a pesquisa se torna um retrato da realidade de várias pequenas empresas do Brasil, onde os seus proprietários e gestores ainda não tem uma compreensão mais aprofundada da importância da adoção das práticas ambientais. Farias e Teixeira (2002) corroboram com esta assertiva nos resultados de pesquisa desenvolvida com as pequenas empresas do vale do São Francisco, em Sergipe, onde os empresários desta região não veem as questões ambientais como parte de sua preocupação, e desconhecem qualquer lei especifica.

Já quando perguntados sobre a importância da adoção de práticas sustentáveis para a melhor imagem da organização perante seus clientes, todos os entrevistados afirmaram positivamente acerca do questionamento, evidenciando assim, uma consciência que a gestão ambiental é positiva em vários aspectos. No tocante ao meio ambiente para os funcionários, os entrevistados afirmaram que existe uma preocupação do proprietário e da gerencia, mas não houve um aprofundamento nas respostas.

\section{CONCLUSÕES}

Tendo em vista o objetivo de verificar o conhecimento dos gestores de pequenas empresas do centro comercial de Aracaju/SE acerca das questões ambientais e relacionar se tal entendimento influencia na aplicação de práticas sustentáveis em seus estabelecimentos este estudo traçou um breve panorama sobre a relevância da educação ambiental e sua correlação com práticas e ações que tencionam a gestão ambiental 
nas mais diversas organizações. O questionário proposto foi aplicado há 40 gerentes de empresas de pequeno porte do centro comercial de Aracaju.

Mediante as análises dos questionários e entrevistas, entendeu-se que o nível de educação ambiental dos 40 gerentes sujeitos deste estudo pode ser classificado como deficitário, pois, os dados apontam para a falta ou o pouco discernimento deles quanto à relevância das ações antrópicas nas questões naturais e desconhecem as macro relações estabelecidas entre o homem e os variados ambientes. Os dados indicam ainda que as práticas ambientais adotadas por eles no âmbito organizacional são meramente ações de curto prazo que objetivam a redução de despesas imediatas sem maior aprofundamento acerca da relevância da educação ambiental no contexto do ambiente de trabalho.

Conforme os relatos, identificou-se que para XX não se faz necessária a realização de planejamento ou projeto voltado para a gestão ambiental, haja vista acreditarem que ações pontuais e não contínuas já configurariam tal aspecto. Por fim, é possível notar uma nuance positiva nas falas dos entrevistados no que tange a consciência de que a responsabilidade ambiental é valiosa tanto para sociedade quanto para imagem da empresa, conferindo importância ao fator social de atrelar marca e/ou empresa às temáticas socioambientais.

Com isso, é possível associar que o nível de educação ambiental dos gestores das organizações participantes deste estudo influência de maneira direta na adoção, ou não, de práticas sustentáveis em sua gestão e, consequentemente, nas ações e comportamentos dos funcionários enquanto práticas cotidianas a serem desenvolvidas, motivadas e aprimoradas. Diante do exposto, ressalta-se que a educação ambiental na formação profissional é vista como fundamental para a formação de empreendedores sustentáveis, pois é notório que as empresas são proporcionalmente os maiores poluidores da sociedade.

\section{REFERÊNCIAS}

ARAUJO, C. G.; MENDONÇA, M. S. P.. Analise do Processo de Implantação das Normas de Sustentabilidade Empresarial: um estudo de caso em uma agroindústria frigorífica de bovinos. Revista de Administração Mackenzie. v.10, n.10, n.2, 2009.

ALPERSTEDT. D, G.; QUINTELLA, H. R.; SOUZA, R. L.. Estratégias de Gestão Ambiental e seus fatores determinantes: Uma Análise Institucional. Revista de Administração de Empresas. São Paulo, v.50, n.2, p.170-186, 2010.

ANDRADE, R. O. B.; CARVALHO, A. B.; TACHIZAWA, T.. Gestão ambiental: enfoque estratégico aplicado ao desenvolvimento sustentável. 2.ed. São Paulo: Makron Books, 2002.

ANTONIK, L. R.. A Administração financeira das pequenas e medias empresas. Revista FAE BUSINESS. n.8, p.35-38, 2004.

BARBIERI, J. C.; VASCONCELOS, I. F. G.; ANDREASSI, T.; VASCONCELOS, F. C.. Inovação e Sustentabilidade: Novos Modelos e Proposições. Revista de Administração de Empresas. São Paulo, v.50, n.2, p.146-154, 2010.
BASSETTO, I. L.. A Incorporação da Responsabilidade social e sustentabilidade: um estudo baseado no relatório de gestão 2005 da companhia paranaense de energia-COPEL. Revista Gest. Prod. São Carlos, v.17, n.3, p.639-651, 2010.

BENEDICTO, D. C. S.; RODRIGUES, A.; PENIDO, S. D. M. A.; AVELAR, L. H. P.. Programas de Gestão Ambiental nas Organizações: Uma reflexão teórica sobre a sua necessidade e importância. Revista Eletrônica FEOL, v.1, n.2, 2011.

BOWEN, H. R.. Responsibility of the businessman. New York: Harper \& Row, 1953.

BORGES, S. L. F.; GALLI, A. L. C. L.; TAMASHIRO, S. R. H.. Responsabilidade social corporativa: um estudo de múltiplos casos com pequenas empresas do setor sucroalcooleiro da região de ribeirão preto. Revista de Gestão social e ambiental-RGSA. São Paulo, v.6, n.1, p.70-86, 2012.

BRUNELLI, M.; COHEN, M.. definições, diferenças e semelhanças entre empreendedorismo sustentável e ambiental: análise do estado da arte da literatura entre 1990 e 2012. In: ENANPAD. 34. Anais. Rio de Janeiro: ANPAD, 2012. 
CARRIERI, P. A.; SILVA, L. R. A.; PIMENTEL, D. T.. O Tema da Proteção Incorporado nos Discursos da Responsabilidade Social Corporativa. Revista de Administração

Contemporânea. Curitiba, v.13, n.1, p.1-16, 2009.

CAMPOS, S. M. L.; MELO, A. D.; SILVA, C. M.; FERREIRA, E.. Os Sistemas de Gestão Ambiental: empresas Brasileiras certificadas pela norma ISO 14001. In: Encontro Nacional de Engenharia de Produção. 24. Anais. Fortaleza: ENGEP, 2006.

DALMORO, M. A.. Visão da Sustentabilidade na Atividade empreendedora: uma analise a partir de empresas incubadas. Revista Gestão Organizacional. v.2, n.1, 2009.

FARIAS, S. J.; TEIXEIRA, M. R.. As Pequenas e micro empresa e o meio ambiente: a percepção dos empresários com relação aos impactos ambientais. Revista OES. Salvador, v.9, n.23, 2002.

GIL, C. A.. Como Elaborar Projetos de Pesquisa. 4 ed. São Paulo: Atlas, 2002.

IBGE. Instituto Brasileiro de Geografia e Estatística. Pesquisa Anual do Comercio. Rio de Janeiro: IBGE, 2010.

IBGE. INSTITUTO BRASILEIRO DE GEOGRAFIA E ESTATISTICA. As Micro e Pequenas Empresas Comerciais no Brasil 2001. Rio de janeiro: IBGE, 2003

JABBOUR, C. J. C.; SANTOS, F. C. A.; BARBIERI, J. C.. Gestão ambiental empresarial: um levantamento da produção da produção científica brasileira divulgada em periódicos da área de administração entre 1996 e 2005. Revista de Administração Contemporânea, v.12, n.3, p.689-715, 2008.

LAKATOS, M. A.; MARCONI, A. D. M.. Fundamentos de Metodologia Cientifica. 5 ed. São Paulo: Atlas, 2003.

MENDONÇA, F.. S. A. U - Sistema Socioambiental Urbano: uma abordagem dos problemas socioambientais da cidade. In: MENDONÇA, F.. Impactos socioambientais urbanos. Curitiba: UFPR, 2004.

MORESI, E.. Metodologia de Pesquisa. Brasília: Universidade Católica de Brasília UCB, 2003.

NOGUEIRA, O.. Pesquisa social: introdução às suas técnicas. São Paulo: EDUSP, 1968.

OLIVEIRA, J. O.. Pequenas empresas no Brasil: um estudo de suas características e perspectivas. Revista Integração. v.7, n.44, p.5-15, 2006

ROESCH, S. M. A.. Projetos de estagio e de pesquisa em Administração: guia para estágios, trabalhos de conclusão, dissertações e estudos de casos. 3 ed. São Paulo: atlas, 2005.

SEBRAE. Serviço Brasileiro de Apoio a Micro e Pequenas Empresas. O Que Pensam as Micro e Pequenas Empresas Sobre Sustentabilidade. Brasília, 2012.
SEBRAE. Serviço Brasileiro de Apoio a Micro e Pequenas Empresas. Anuário do Trabalho na Micro e Pequena Empresa. 4 ed. São Paulo, 2011.

SILVA, J. O.; SOUZA, R. P.; ROCHA, I.; HEIN, N.. Evidenciação das Informações Ambientais utilizando os Indicadores do Instituto Ethos: Análise das Empresas que compõem o ISE desde sua primeira formação. In: Seminários de Administração. 7. Anais. São Paulo: SEMEAD, 2010.

STEFFEN, S. D.; WEYH, B. C.; REIS, R. H.; SANTOS, D. K. M.; QUINTERO, J. A. J.. The Environmental Management as a Business Value in Small Companies. Algarve: Tourism and Management Studies International Conference Algarve 2012

TACHIZAWA, T.. Sustentabilidade e Responsabilidade Social: Proposta de modelo de Diagnóstico Socioambiental Baseada em Pesquisa Empírica. Revista da Associação Brasileira de Engenharia de Produção. Santa Catarina, v.4, n.4, 2009.

TACHIZAWA, T.; POZO, H.. Gestão socioambiental e desenvolvimento sustentável: um indicador para avaliar a sustentabilidade empresarial. Revista Eletrônica do Prodema, Fortaleza, v.1, n.1, p.35-54, 2007.

TAUK, S. M.. Análise Ambiental: Uma visão multidisciplinar. São Paulo: Unesp, 2003

TAVARES, B.; LIMA, C. A.; SILVEIRA, R. F. S.. Características Gerenciais das Micro e Pequenas Empresas e as de seus Empreendedores: Alternativas para Gestão Financeira. In: Simpósio de Excelência em Gestão e Tecnologia. Anais. Minas Gerais: SEGeT, 2011.

TINOCO, J. E. P.; KRAEMER, M. E. P.. Contabilidade e gestão ambiental. São Paulo: Atlas, 2004

VERGARA, S. C.. Projetos e relatórios de pesquisa em administração. 7 ed. São Paulo: atlas, 2006.

YOUNG, W.; TILLEY, F.. Can businesses move beyond efficiency? The shift toward effectiveness and equity in the corporate sustainability debate. Business Strategyandthe Environment, v.6, n.15, p. 402-415, 2006.

KOTESKI, M. A.. As Micro e Pequenas Empresas no Contexto Econômico Brasileiro. Revista FAE Business, v.1, n.8, 2004.

YIN, R. K.. Estudo de caso: planejamento e método. 2 ed. Porto Alegre: Bookman, 200

GOODFELLOW, J.. O papel do contador em relação ao meio ambiente e ao desenvolvimento sustentado. Revista Brasileira de Contabilidade. Brasília, v.27, n.110, 2000.

PEDRINI, A. G. P.. Educação ambiental empresarial no Brasil. São Carlos: Rima, 2008.

REIGOTA, M.. O que é educação ambiental. 2. ed. São Paulo: Brasiliense, 2009 